\title{
GASTRIC VARICEAL OBLITERATION BY CYANOACRYLATE GLUE INJECTION
}

\author{
Hussain $\mathrm{SMB}^{1}$, Hossain $\mathrm{MR}^{2}$, Rahman $\mathrm{MM}^{3}$, Parvin $\mathrm{S}^{4}$, Hossain $\mathrm{MD}^{5}$
}

\begin{abstract}
Introduction: Rupture Gastric varices (GVs) can lead to catastrophic gastrointestinal bleeding, though it is much less in number than that of rupture oesophageal varices (OVs). Successful haemostasis of such bleeding is difficult specially in the back ground of non availability of appropriate drugs and instruments.

Case Report: Introduction of intra-variceal injection of cyanoacrylate glue since 1980 s has changed the scenario, it is cheaper and effective in controlling GVs related bleeding. A case of successful control of gastric variceal bleeding is reported.
\end{abstract}

Key words: Gastric varices, bleeding, haemostasis

\section{Introduction}

Gastric varices (GVs) are less common than oesophageal varices (OVs). Generally $20 \%$ of portal hypertension harbour GVs and only a few of them bleeds ${ }^{1}$. Unfortunately, bleeding GVs are catastrophic and usually present with massive upper gastro-intestinal (GI) bleeding ${ }^{1}$. Many techniques have been tried to control GVs related bleeding. Rubber band ligation or sclerotherapy are not effective enough to control GVs related bleeding like OVs related bleeding ${ }^{2}$. Non-endoscopic methods, such as trans-jugular intrahepatic portosystemic shunt (TIPS), balloon occluded retrograde trans-venous obliteration (BORTO) and surgical portosystemic shunts are effective but expansive, highly technical and not available in Bangladesh $^{3}$. Moreover emergency shunt carries a high rate of postoperative mortality. The discovery of tissue adhesive cyanoacrylate has changed the management of gastric variceal bleeding since $1980 \mathrm{~s}^{3}$. A successfully completed gastric variceal obliteration (GVO) by applying intravariceal injection of cyanoacrylate glue is reported in this paper.

\section{Case Report}

A 45 years old female patient presented with haematemesis and melaena for 02 days. Detail history and clinical examination revealed that she was severely anaemic $(\mathrm{Hb} \%$ $7.5 \mathrm{gm} / \mathrm{dl}$ ), hypotensive (blood pressure 100/60 mm of $\mathrm{Hg}$ ), nonicteric (bilirubin $0.8 \mathrm{mg} / \mathrm{dl}$ ), with $5 \mathrm{~cm}$ enlarged spleen. There was no peripheral oedema or ascites. Neither liver was palpable nor had any spider angiometa. Her Alanine transaminase (ALT) was $132 \mathrm{IU} / \mathrm{L}$, prothrombin time was normal with control with international normalized ratio (INR) 2.5. Ultrasonogram of hepatobiliary system was suggestive of cirrhosis of Liver with portal hypertension. After initial resuscitation with intravenous (iv) infusion, blood transfusion, upper GI endoscopy was done that revealed three isolated fundic varices with red spot (Fig 1). Then $3 \mathrm{ml}$ cyanoacrylate glue diluted in lipiodal in the ratio of 2:3 was injected intravariceally with the help of commercially flexible sclerotherapy injector $(6 \mathrm{~mm}, 21$ gauge needle) slowly (Fig 2). The needle was flushed with lipiodal and endoscope was withdrawn gently keeping the needle out of endoscope tip. The patient was kept under follow up for next one week with standard medical treatment for her cirrhosis. There was no evidence of further blood loss or fall of haemoglobin. As there was no immediate or late complication of variceal injection she was discharged with advice to attend out patient department, follow up endoscopy was done after two weeks which revealed total obliteration of GVs. Subsequently she is under standard treatment for her cirrhosis of liver and portal hypertension and is followed up three monthly for recurrence of any oesophageal or gastric varix.

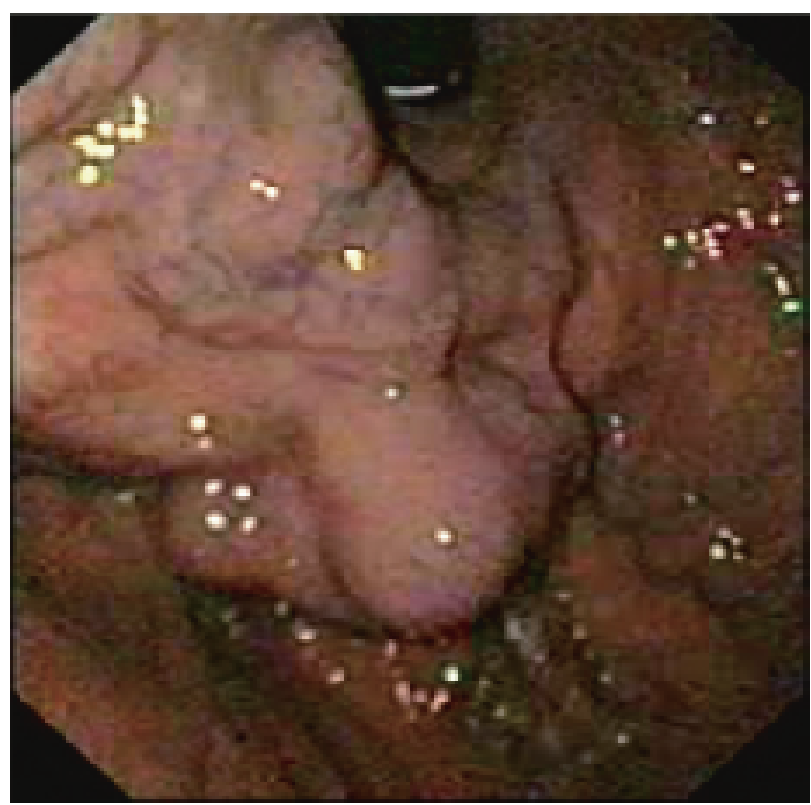

Fig-1: Isolated gastric varices in fundus of stomach

1. Brig Gen Sk Md Bahar Hussain MBBS, FCPS, FRCP (Edin), FRCP (Glasg), FACP (USA), Adviser Specialist in Medicine, CMH Chittagong; 2. Maj Gen Md Rabiul Hossain MBBS, MCPS, FCPS, FRCP (Edin), Consultant Physician General, Bangladesh Armed forces; 3. Brig Gen Md Moklesur Rahman MBBS, FCPS, Professor of Medicne, AFMC; 4. Lt Col Saila Parvin MBBS, MCPS, FCPS, Classified Specialist in Medicine, Bangladesh Naval Service Hospital, Patenga; 5. Lt Col Md Delwar Hossain MBBS, FCPS, FCPS, Graded Specialist in Medicine, CMH Chittagong. 


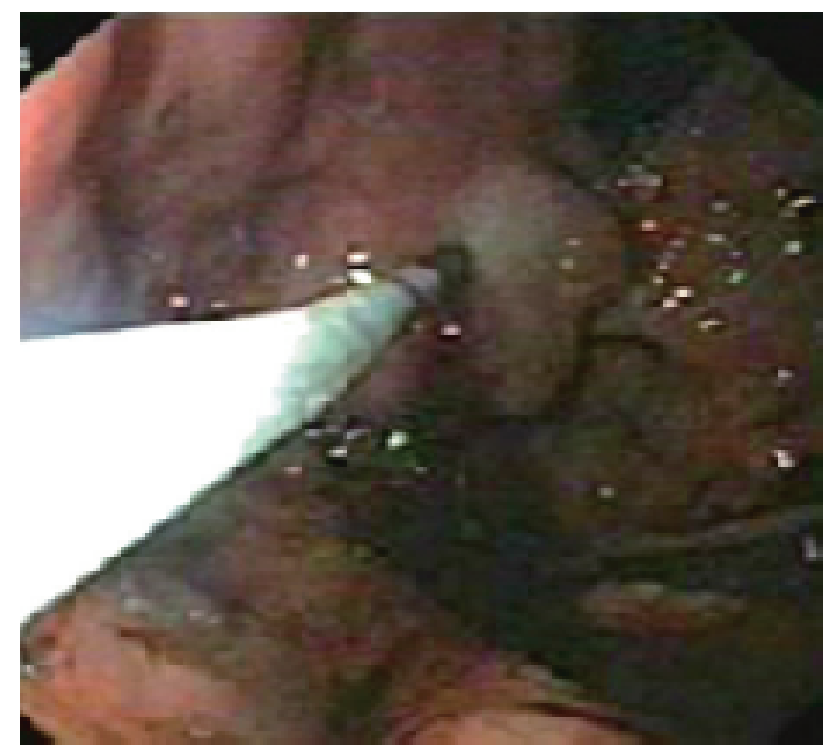

Fig-2: Intravariceal injection of cyanoacrylate glue

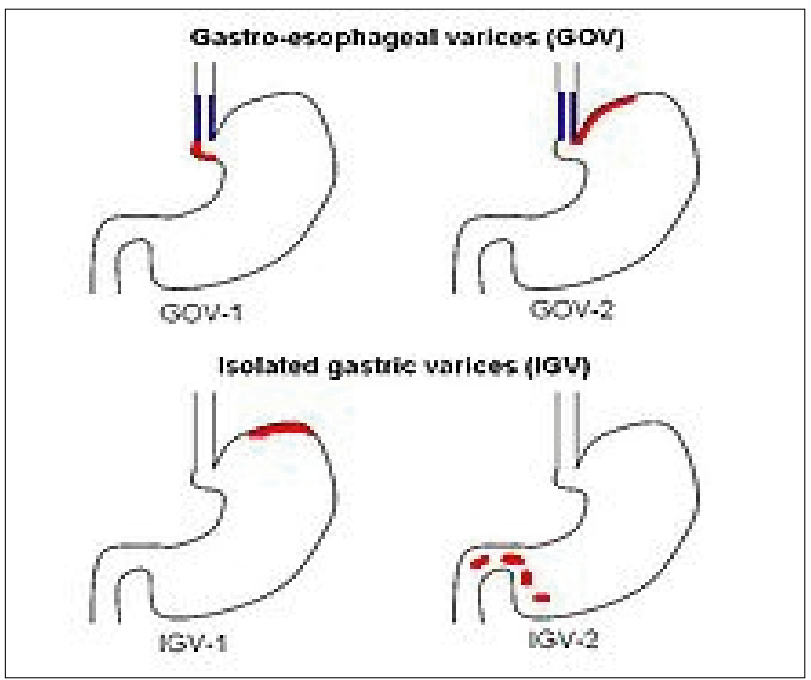

Fig-3: Sarin's classification of gastric varices as per its position

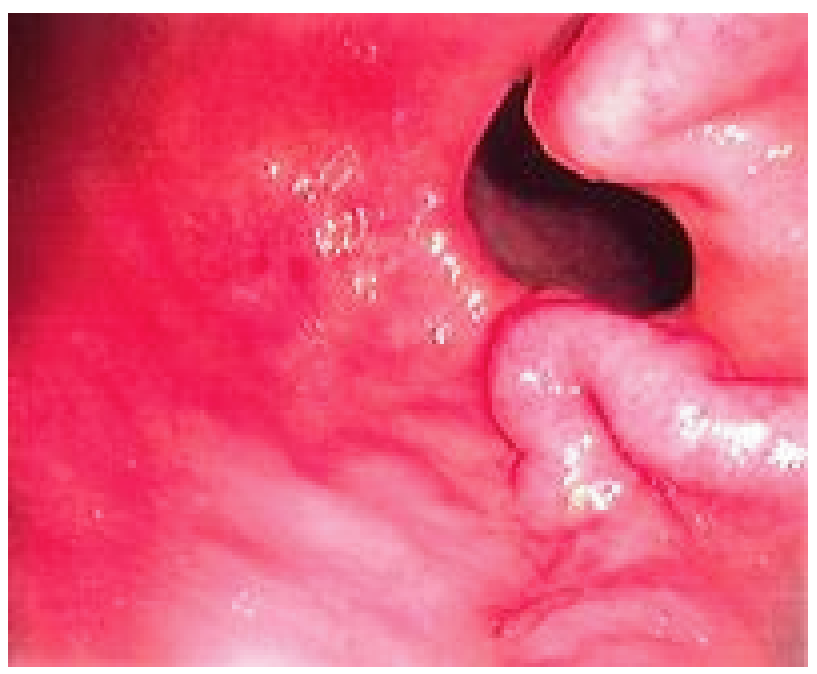

Fig-4: Isolated gastric varices near pylorus (IGV- 2)

\section{Discussion}

Gastric varices develops mainly in fundus of the stomach which is much less common than of oesophageal varices. According to the site of the varices they are four types ${ }^{1}$ (Fig-3). Twenty percent of patients with portal hypertension develop gastric varices and it accounts for $10-20 \%$ of all variceal bleeding ${ }^{1}$. It can also be developed from extra hepatic portal vein obstruction mainly due to pancreatitis or in pancreatic neoplasm ${ }^{4}$. The risk of GVs bleeding is less but whenever bleeding occurs, it is dangerous and may be fatal, again it is associated with higher (34-89\%) rate of rebleeding1. In the reported case it was due to hepatitis B virus (HBV) induced cirrhosis of liver with portal hypertension. Unlike OVs, endoscopic technique to control gastric variceal bleeding is very difficult due to the awkward position of the scope and size of GVs. GV which is larger than $2 \mathrm{~cm}$ in diameter may be difficult to suck into the tip of the scope while performing endoscopic variceal ligation (EVL). Therefore, incomplete endoscopic ligation may occur. The residual varix with high pressure may be prone to recurrent bleeding. All of the therapeutic devices have to come from retroflex position. In addition, blood in the fundus may obscure the view. A recent study reported by Lo et al concluded that endoscopic obliteration using band ligation is less effective and more difficult than cyanoacrylate injection in the management of bleeding $\mathrm{GVs}^{5}$. Apart from endoscopic treatment, TIPS is the best alternative to control GVs bleeding ${ }^{6}$. Unfortunately, TIPS is not widely available in Bangladesh. Endoscopic obliteration of GVs to achieve haemostasis has been reported from many centres around the world. Variety of sclerosing agents were used including alcohol, tissue thrombin and cyanoacrylate $^{5}$. Endoscopic intravariceal injection by other agents beside cyanoacrylate such as alcohol appeared to be less effective and need for rescue surgery $^{7}$. In this case intravariceal injection of cyanoacrylate glue was used to obliterate the bleeding varices and could achieve haemostasis in the first session. There have been reports that cyanoacrylate injection could control GVs bleeding with excellent results6. First session of cyanoacrylate glue injection in sufficient enough to achieve definite haemostasis, second session of cyanoacrylate glue injection may require but is less effective8. It is found that who failed to achieve definite haemostasis had more advanced liver disease or had hepatocellular carcinoma $(\mathrm{HCC})^{7}$. Cyanoacrylate injection related complications are generally minor and spontaneously resolved such as epigastric discomfort, nausea, vomiting and ulcer at the site of injection, fever, sepsis, retroperitoneal abscess and distal embolization ${ }^{8}$. There are reports of cerebral embolism, pulmonary embolism, embolisms in the abdominal vessels and even in left atrium ${ }^{9}$. To minimize the septic process some of the authorities used prophylactic antibiotics ${ }^{10}$. 


\section{Conclusion}

Endoscopic intravariceal injection of cyanoacrylate glue is effective to control majority of GVs related bleeding. It is easy to apply, less expensive, most effective and have less chance of complication. Advanced stage cirrhosis and $\mathrm{HCC}$ are major risk factors for failed haemostasis after cyanoacrylate injection for GVs.

\section{References}

1. Serin SK, Lahoti D, Saxena SP, et al. Prevalence, Classification and natural history ogastric varices; a long term follow-up study in 568 portal hypertension patients. Hepatology 1992; 16: 1343 - 49.

2. Noophun P, Kongkam P, Gonlachanvit S, et al. Bleeding gastric varices: results of endoscopic injection wiyh cyanoacrylate at King Chulalongkorn Memorial Hospital. World J Gastroenterol 2005; 11(47): $7531-35$.

3. Jutabha R, Jensen DM, Egan J, et al. Randomized, prospective study of cyanoacrylate injection, sclerotherapy or rubber band ligation for endoscopic haemostasis of bleeding gastric varices. Gastrointest Endosc 1995; 41: $201-05$.
4. Pugh RN, Murray-Lyon IM, Miyazaki S, et al. Transection of the oesophagus for bleeding oesophageal varices. Br J Surg 1973; 60: 646 649.

5. Lo GH, Lai KH, Chen JS, et al. A prospective, randomized trial of butyl cyanoacrylate injection versus band ligation in the management of bleeding gastric varices. Hepatology 2001; 33: 1060 - 64 .

6. Sarin SK. Long-term follow-up of gastric variceal sclerotherapy: an eleven years experience. Gastrointest Endosc 1997; 46: 8 - 14.

7. Huang YH, Yeh HZ, Chen GH, et al. Endoscopic treatment of bleeding gastric varices by N-butyl-2-cyaniacrylate injection: long term efficacy and safety. Gastrointest Endosc 2002; 55: 276 - 78.

8. Tan PC, Hou MC, Lin HC, et al. A randomized trial of endoscopic treatment of acute gastric variceal haemorrhage: N-butyl-2 cyanoacrylate injection versus band ligation. Hepatology 2006; 43: 690 m- 97.

9. Gallet B, Zemour G, Saudemont JP, et al. Echocardiographic demonstration of intracardiac glue after endoscopic obliteration of gastroesophageal varices. J Am Soc Ecocardiogr 1995; 8: 759 - 61.

10. Bernard B, Grange JD, Khac EN, et al. Antibiotic prophylaxis for the prevention of bacterial infection in cirrhotic patients with gastrointestinal bleeding: a meta analysis> Hepatology 1999; 29: 1655 61 . 